\title{
Prediction of lymph node metastasis in papillary thyroid cancer by preoperative BRAF analysis, Is it useful?
}

A. Luque ${ }^{1}$, J. Sastre ${ }^{1}$, F. del Val ${ }^{1}$, C. Cortés ${ }^{1}$, I. Luque ${ }^{1}$, E. Maqueda ${ }^{1}$, A. Vicente ${ }^{1}$, V. Peña ${ }^{1}$, E. Castro ${ }^{1}$, MA. Morlan ${ }^{2}$, Y. Campos ${ }^{3}$, J. López ${ }^{1}$. Endocrinology Department ${ }^{1}$, Surgery Department ${ }^{2}$, Genetic Department ${ }^{3}$. Hospital Virgen de la Salud. Toledo. Spain

\section{Introduction and Aim}

Prophylactic central lymph node dissection (CLND) in patients with suspected papillary thyroid cancer (PTC) without evident lymph node metastasis (LNM), remains debatable. We propose to evaluate whether BRAF V600E mutation presence, could help to identify patients at risk for LNM.

\section{Methods}

Retrospective study of patients with diagnosis of differentiated thyroid cancer, who underwent total thyroidectomy during 2002 and 2013 (n:256) in our hospital. Patients with pathological diagnosis of PTC, whose BRAF V600E mutation status was known (n:170) and who underwent lymphadenectomy (n:118) as well, were selected.

LNM presence was correlated with BRAF V600E mutation status (presence of BRAF V600E mutation vs wild type) and with other clinico-pathological factors (age, initial tumor size, gender, etc).

A multivariate analysis was performed to assess independent factors related to LNM.

DNA was extracted from paraffin-embebbed tissues section and V600E mutations were detected by HRM followed by sequencing confirmation.

\section{Results}

Table 1: Demographic and pathological characteristics of the cohort

\begin{tabular}{|c|c|}
\hline Gender: female / male (n,\%) & $88(74,6 \%) / 30(25,4 \%)$ \\
\hline Age at diagnosis (years) & $44,8 \pm 15,5^{*}$ \\
\hline Time from diagnosis (months) & $42,0 \pm 29,1^{*}$ \\
\hline Classical PTC (n, \%) & $86(72,9 \%)$ \\
\hline Lymph node metastasis (n ,\%) & $71(60,2 \%)$ \\
\hline Extrathyroidal invasion (n ,\%) & $43(36,8 \%)$ \\
\hline Distant metastasis (n,\%) & $6(6,6 \%)$ \\
\hline AJCC stage (n, \%) & $66(55,9 \%)$ \\
I & $12(10,2 \%)$ \\
II & $13(11,0 \%)$ \\
III a & $18(15,3 \%)$ \\
IV c & $3(2,5 \%)$ \\
Unknown & $6(5,1 \%)$ \\
\hline
\end{tabular}

* Data expressed as median $\pm \mathrm{sd}$

Figure 2: BRAF mutation status and presence of LNM Univariate analysis

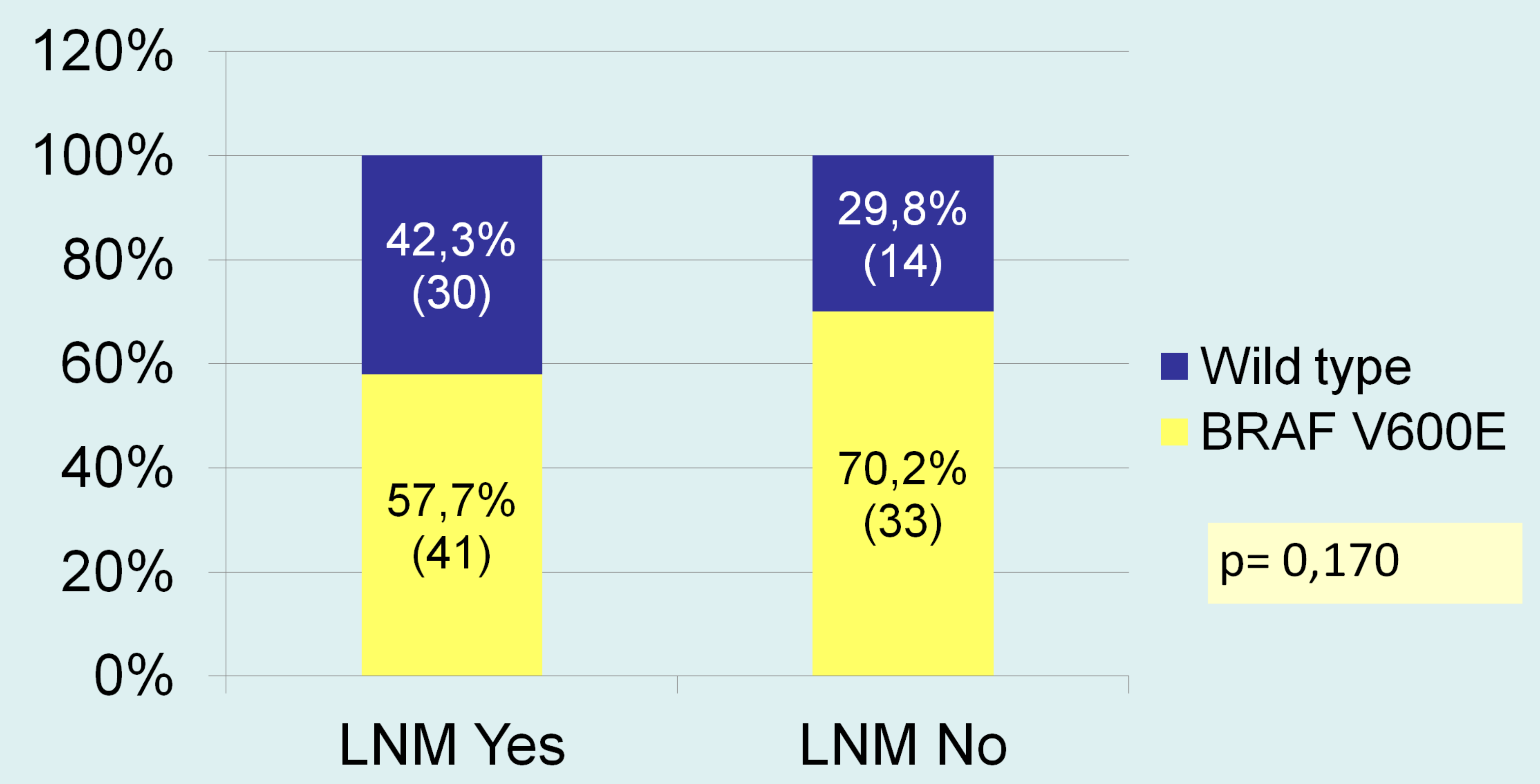

Figure 1: Prevalence of BRAF V600E mutation

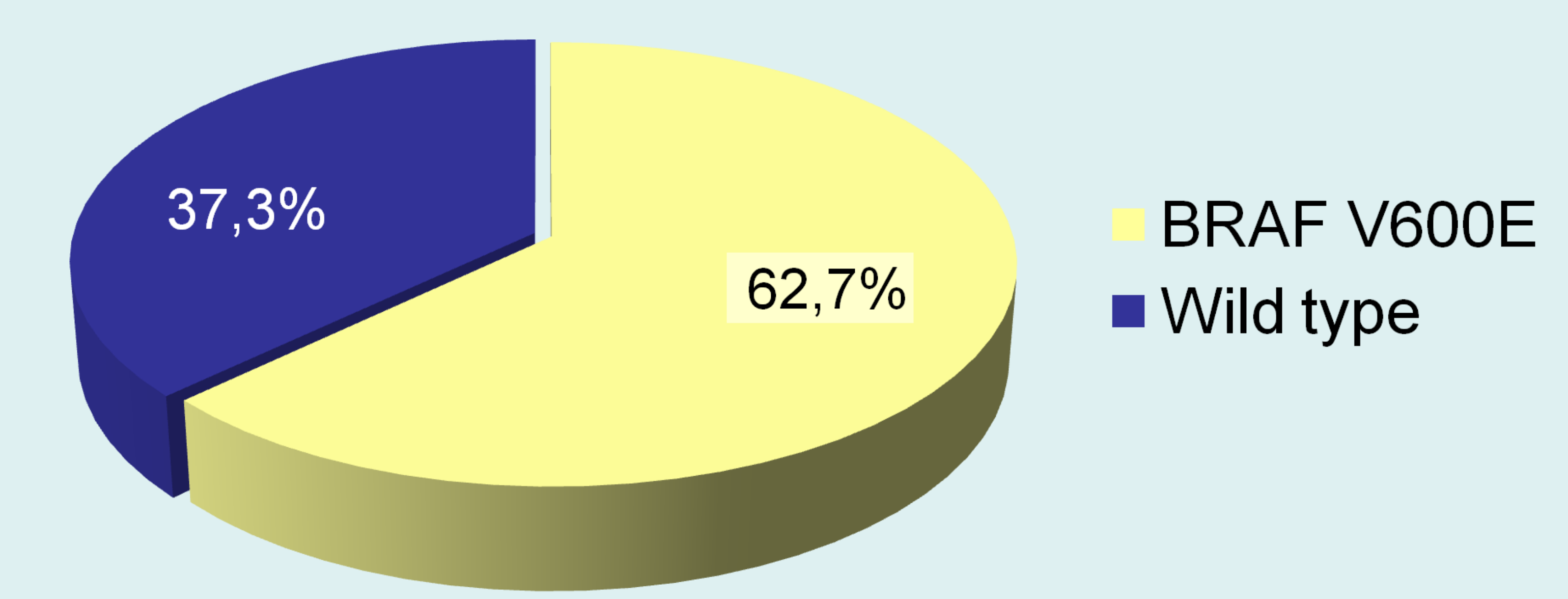

Table 2: Characteristics associated with LNM Univariate analysis

\begin{tabular}{|l|c|c|c|}
\hline & LNM YES & LNM NO & P \\
\hline Age $>$ 45 years & $52,0 \%$ & $48 \%$ & 0,120 \\
\hline Male Sex & $76,7 \%$ & $23,3 \%$ & $<\mathbf{0 , 0 5}$ \\
\hline Size $>1 \mathrm{~cm}$ & $59,5 \%$ & $40,5 \%$ & 0,914 \\
\hline Size $>2 \mathrm{~cm}$ & $66,7 \%$ & $33,3 \%$ & 0,233 \\
\hline Extrathyroidal invasion & $74,4 \%$ & $25,6 \%$ & $<\mathbf{0 , 0 5}$ \\
\hline Multifocality & $42,6 \%$ & $57,4 \%$ & 0,187 \\
\hline
\end{tabular}

Tabla 3 Multivariate analysis: Variables independently associated with the presence LNM

\begin{tabular}{l|c|c|c} 
& OR & $\mathbf{C I} \mathbf{9 5} \%$ & $\mathbf{p}$ \\
\hline Extrathyroidal invasion & $\mathbf{3 , 0}$ & $\mathbf{1 , 8 - 7 , 9}$ & $\mathbf{0 , 0 5}$ \\
\hline Female sex & 0,35 & $0,12-1,04$ & 0,057 \\
\hline Age $>$ 45 years & 2,23 & $0,92-5,3$ & 0,073 \\
\hline BRAF V600E & 0,61 & $0,25-1,46$ & 0,269 \\
\hline Size $<2 \mathrm{~cm}$ & 0,74 & $0,31-1,81$ & 0,515 \\
\hline Multifocality & 1,2 & $0,52-3,01$ & 0,616
\end{tabular}

\section{Conclusions}

Our results do not support using the presence of V600E mutation to decide whether to perform or not prophylactic CLND in patients with PTC. More prospective studies will be necessary. 